\title{
A New Liquid Chromatography-Tandem Mass Spectrometry Method for Determination of Bisoprolol in Human Plasma Samples
}

\author{
Gabriela Peste, ${ }^{1}$ Nela Bibire, ${ }^{2}$ Mihai Apostu, ${ }^{2}$ Aurel Vlase, ${ }^{1}$ and Corneliu Oniscu ${ }^{3}$ \\ ${ }^{1}$ Center for Drug Evaluation, Antibiotice S.A., Valea Lupului, 1 Street, 707410 Iasi, Romania \\ ${ }^{2}$ Department of Analytical Chemistry, Faculty of Pharmacy, "Gr.T. Popa" University of Medicine and Pharmacy, 700115 Iasi, Romania \\ ${ }^{3}$ Faculty of Chemical Engineering and Environment Protection, Technical University "Gheorghe Asachi”, \\ 71 st A Mangeron Dimitrie Street, 7000050 Iasi, Romania \\ Correspondence should be addressed to Gabriela Peste, gabrielapeste@yahoo.com \\ Received 6 March 2009; Revised 2 June 2009; Accepted 10 June 2009 \\ Recommended by Kennerly S. Patrick
}

Liquid chromatography (LC) coupled with mass spectrometry (MS) detection is one of the most powerful analytical tools for organic compound analysis. The advantages of using LC/MS methods over HPLC methods include: selectivity, chromatographic integrity, peak assignment, structural information, and rapid method development. In this paper, a new liquid chromatographytandem mass spectrometry (LC-MS/MS) method has been developed and validated for the determination of bisoprolol in human plasma samples, using metoprolol as internal standard and liquid-liquid extraction procedure. The assay has proven to be sensitive, specific and reproducible, suitable to determine the bisoprolol concentration, following a single oral administration of a $10 \mathrm{mg}$ bisoprolol tablet in 22 healthy volunteers, in the bioequivalence study of Bisoprolol $10 \mathrm{mg}$ coated tablets, produced by Antibiotice S.A. versus Concor $10 \mathrm{mg}$, produced by Merck.

Copyright () 2009 Gabriela Peste et al. This is an open access article distributed under the Creative Commons Attribution License, which permits unrestricted use, distribution, and reproduction in any medium, provided the original work is properly cited.

\section{Introduction}

Bisoprolol fumarate is a synthetic cardioselective $\beta_{1}$ adrenergic blocker. Chemically, bisoprolol fumarate is $( \pm)$ 1-[4-[[2-(1-methylethoxy)ethoxy] methyl]phenoxy]-3-[(1methylethyl)amino]-2-propanol(E)-2-butenedioate (2 : 1) [1]. It possesses an asymmetric carbon atom in its structure and is provided as a racemic mixture. The $S(-)$ enantiomer is responsible for most of the beta-blocking activity.

The objectives of this work were to develop and to validate a simple, accurate, rapid and economic LC-tandem mass spectrometry method for the determination of bisoprolol in human plasma samples, using liquid-liquid extraction, and to present some of this method applications.

\section{Materials and Methods}

2.1. Instruments. All analyses were performed using the Agilent 1100 LC/MSD Trap XCT system. The system com- penents included the Agilent 1100 Degasser, Agilent 1100 Binary Pump, Agilent 1100 Autosampler, Agilent 1100 Mass Selective Detector. The Bruker Daltonik software was used for system control and data acquisition. An analytical balance Mettler-Toledo XP56, a Sigma 2-16 K centrifuge and a Vibramax 110 shaker were used for the sample preparation.

The separation was performed using a reverse phase column (Zorbax SB-C18 Solvent Saver Plus, $3 \times 100 \mathrm{~mm}$, $3.5 \mu \mathrm{m}$, supplied by Agilent, USA).

2.2. Reagents. All solvents and other chemicals (acetonitrile, methanol, sodium hydroxide, tert-butyl methyl ether, water, formic acid) were HPLC grade provided by Merck's Chemical Co., Darmstadt, Germany. The reference substances of bisoprolol and metoprolol (internal standard) were supplied from the USP Pharmacopoeia. The human plasma was obtained from Center for Blood Drawing and Preservation, Iasi, Romania. 
2.3. Bisoprolol Stock Solution. Bisoprolol was dissolved in methanol, obtaining a bisoprolol stock solution of $500 \mu \mathrm{g} / \mathrm{mL}$.

2.4. Metoprolol Stock Solution. The internal standard, metoprolol, was dissolved in methanol, obtaining a metoprolol stock solution of $500 \mu \mathrm{g} / \mathrm{mL}$.

2.5. Solutions for Linearity Response. Eight bisoprolol concentrations were prepared in human plasma, covering the expected range of observed concentrations $(1-100 \mathrm{ng} / \mathrm{mL})$. The theoretical concentrations of bisoprolol calibration standards were $1.0,2.0,10.0,20.0,40.0,60.0,80.0$, and $100.0 \mathrm{ng} / \mathrm{mL}$.

2.6. Quality Control Samples. Plasma samples having bisoprolol theoreticals concentrations of $3 \mathrm{ng} / \mathrm{mL}, 25 \mathrm{ng} / \mathrm{mL}$ and $75 \mathrm{ng} / \mathrm{mL}$ were considered to be appropriate to be used to validate the bioanalytical method.

2.7. Samples for Recovery. In order to determine the analyte and the internal standard recovery from the plasma, water samples containing the same bisoprolol concentrations as the quality control samples were prepared.

2.8. Samples Preparation. After alkalization with sodium hydroxide and addition internal standard solution, the $0.250 \mathrm{~mL}$ plasma sample was extracted with $2 \mathrm{~mL}$ tert-butyl methyl ether. The solvent was evaporated using a flow air at $40^{\circ} \mathrm{C}$. The solid residue was dissolved in a $0.250 \mathrm{~mL}$ mixture $0.1 \%$ formic acid solution-acetonitrile (50-50, v/v).

\section{Results and Discussions}

3.1. The Development of the LC-Tandem Mass Spectrometry Method. LC separation of bisoprolol and internal standard, metoprolol, has been carried out using the mobiles phases consisting of differents aqueous solutions and methanol or acetonitrile as organic phase. Hernardo et al. [2] used a acetonitrile as organic mobile phase to lead to shorter retention times and better resolution of the bisoprolol and internal standard. Formic acid solution as additive in water was used by Li et al. [3] to improve the sensitivity of MS detection.

The LC-MS/MS method for determination of bisoprolol in human plasma samples described in this paper was performed using a mobile phase consist in mixture $0.1 \%$ formic acid solution ( $\mathrm{pH} 3$ )-acetonitrile (50-50, v/v). The LC system was operated at $0.3 \mathrm{~mL} / \mathrm{min}$, using the binary pump. The column temperature was $40^{\circ} \mathrm{C}$. The injection volume was $5 \mu \mathrm{L}$ and represented no more $5 \%$ of the total sample available for injection. Short run times of about 3 minutes were achieved for both bisoprolol and internal standard, metoprolol. Bisoprolol was eluted at 1.7 minutes and metoprolol at 1.9 minutes. The peaks of interest were free from interfering peaks at their respective retention time.
To minimize undesirable fragmentation voltages were tested from 80 to $200 \mathrm{~V}$. At $100 \mathrm{~V}$, the MS response of bisoprolol and metoprolol showed both minimal undesirable fragmentation and highest response.

The mass transition ion-pair was followed as $\mathrm{m} / \mathrm{z}$ $326.2 \rightarrow 116.1$ for bisoprolol and $\mathrm{m} / \mathrm{z} 268.2 \rightarrow 191.0$, for metoprolol, as sustained Bhatt et al. [4].

The protonated molecular ion of bisoprolol $[\mathrm{M}+\mathrm{H}]^{+}$ $(\mathrm{m} / \mathrm{z}$ 326.3) was tested to give the highest sensitivity. Based on the optimization results, $\mathrm{m} / \mathrm{z} 116.2$ was selected as the quantifier ion. Also, the protonated molecular ion of metoprolol $[\mathrm{M}+\mathrm{H}]^{+}(\mathrm{m} / \mathrm{z} 268)$ was tested and $\mathrm{m} / \mathrm{z} 116.2$ was selected as the quantifier ion. We have chosen products ions with the same $\mathrm{m} / \mathrm{z}$ value for bisoprolol and metoprolol, respectively, because a possible suppression effect would influence the quantification of both the analyte and internal standard in the same way.

Other mass spectrometric parameters (gas temperature, gas pressure and gas flow) were adjusted to get a maximum signal for bisoprolol. The nebulizing gas flow rate was set at $10 \mathrm{l} / \mathrm{min}$, drying gaz temperature at $350^{\circ} \mathrm{C}$, and the capillary voltage at $4000 \mathrm{~V}$. The response of bisoprolol and metoprolol were measured by MRM in the positive ionization mode with a collision energy of $20 \mathrm{~V}$.

3.2. Validation of the LC-Tandem Mass Spectrometry Method. The method was validated according Guidance for Industry: Bioanalytical Method Validation [5].

The parameters usually examined in the validation process are selectivity/specificity, linearity, limit of quantification, accuracy and precision, stability.

3.2.1. Selectivity. The reversed-phase HPLC method described in this paper has been tested for possible interferences from other plasma factors. Plasma aliquots from six different sources were assessed for analysis in order to investigate the plasma components behavior.

As it can be seen in Figure 1, no overlapping peaks were detected at bisoprolol and internal standard retention time, 1.7 minutes and 1.9 minutes, respectively. The bioanalytical method proved to be selective.

3.2.2. Linearity and Lower Limit of Quantification. The linearity was investigated for a bisoprolol theoreticals concentrations range between $1 \mathrm{ng} / \mathrm{mL}$ and $100 \mathrm{ng} / \mathrm{mL}$ and the calibration curve was derived by plotting the peak-height ratios of the analyte and the internal standard against the concentration of bisoprolol, using linear regression analysis.

The least-square linear regression revealed that the relationship was linear in the investigated domain, with a correlation coefficient of 0.998599 , meeting the acceptance criteria $\left(r^{2} \geq 0,990\right)$, as it can be seen in Figure 2 .

The lower limit of quantification, that is, the lowest standard level with a coefficient of variation less than $20 \%$, is for bisoprolol $0.990 \mathrm{ng} / \mathrm{mL}$ with 41.433 signal to noise ratio. The bioanalytical method proved to be sensitive, allowing a precise quantification of concentrations as low as $1 \mathrm{ng} / \mathrm{mL}$ (see Figure 3). Results are presented in Table 1. 


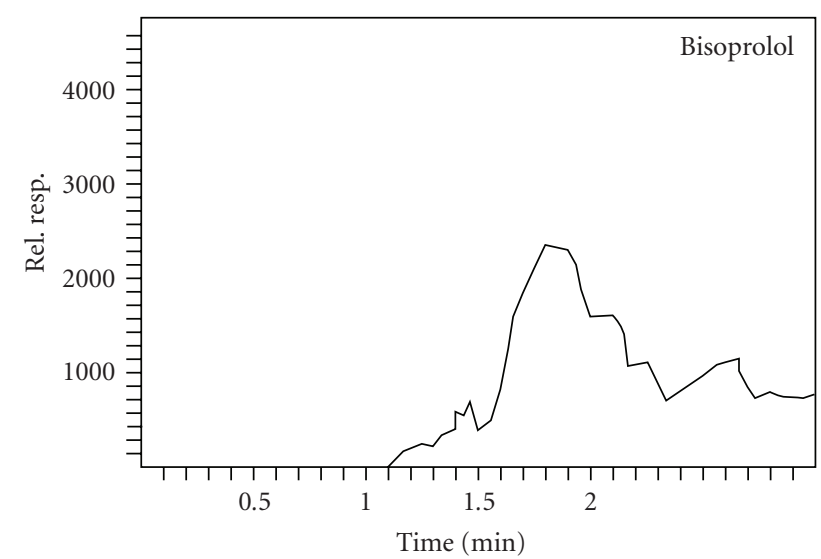

(a)

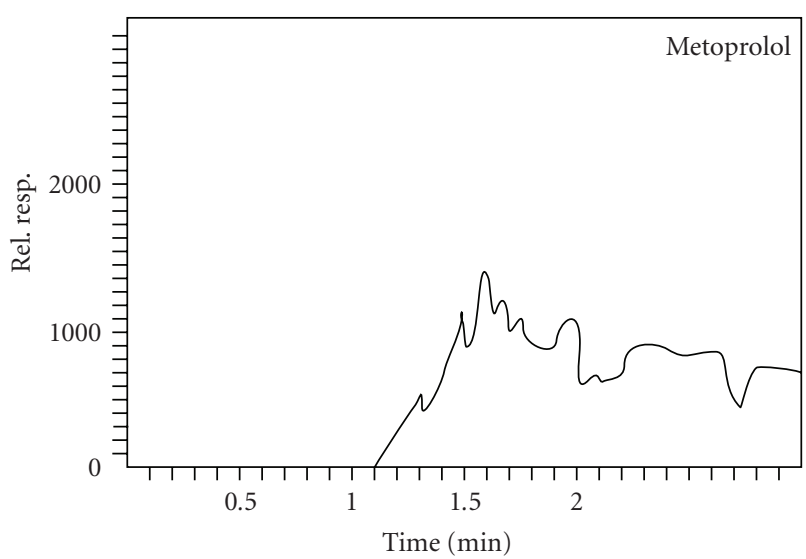

(b)

FIGURE 1: Chromatogram recorded for blank plasma sample.

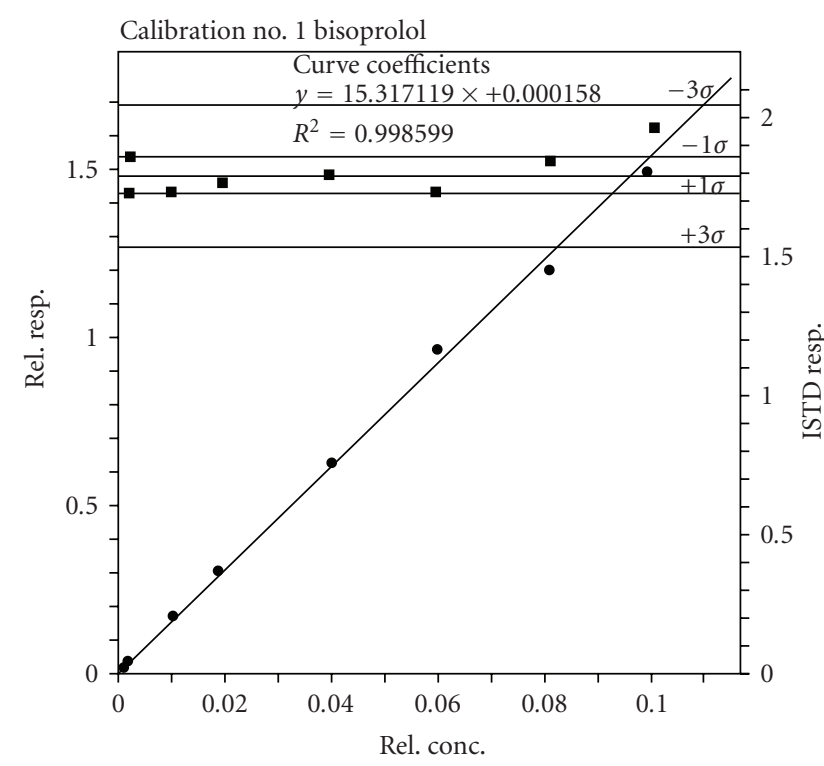

Figure 2: The bisoprolol calibration curve obtained for plasma samples described in Section 2.5.

3.2.3. Accuracy and Precision. Accuracy of the analitycal method represents the degree of closeness of the determined values of an analyte to the nominal/or known true value declared from an individual sample. The accuracy of a bioanalytical method is expressed as a percentage of the nominal value (\% nominal).

Precision of the analitycal method represents the degree of dispersal of the values determined of an analyte, from a series of samples processed and analyzed individually from a homogeneous volume of biological matrix. Precision of a bioanalytical method is expressed as the coefficient of variation of the concerned series of determinations, CV (\%).

The accuracy and precision of this method were calculated for three concentrations of bisoprolol in human plasma. Six replicate samples having bisoprolol theoreticals concentrations of $3 \mathrm{ng} / \mathrm{mL}$ (QC1), $25 \mathrm{ng} / \mathrm{mL}$ (QC2) and

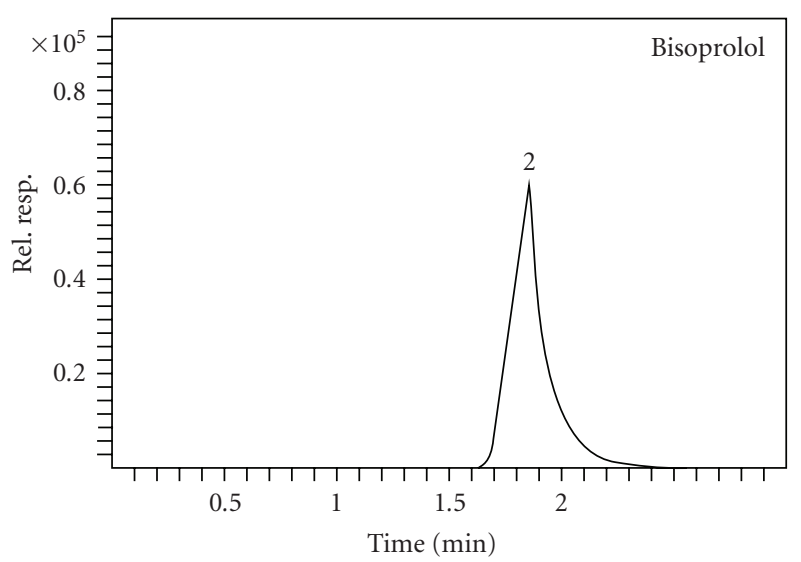

(a)

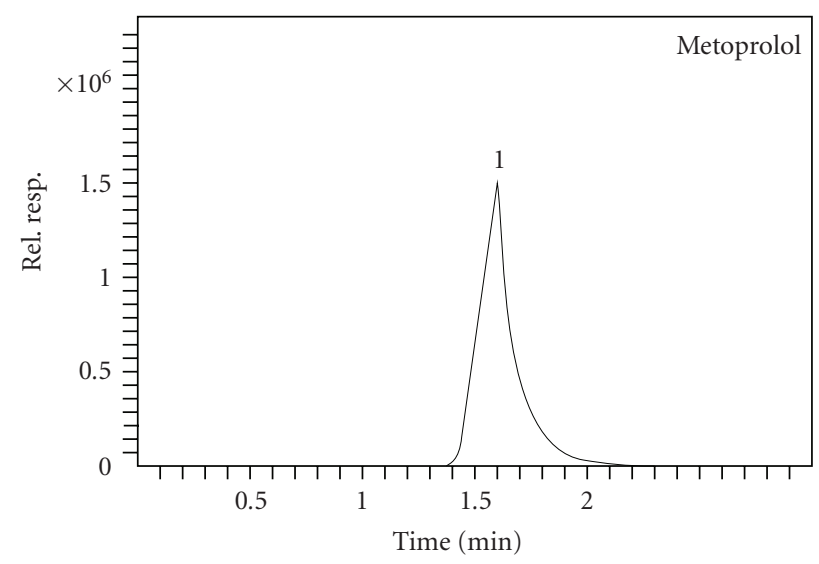

(b)

FIGURE 3: Chromatogram recorded for plasma containing bisoprolol $(0.990 \mathrm{ng} / \mathrm{mL}$, lower limit of quantification) and internal standard.

$75 \mathrm{ng} / \mathrm{mL}$ (QC3) were injected into the system. Table 2 summarizes the results obtained for the intraday parameters. The interday precision and accuracy was evaluated also using 
TABLE 1: Lower limit of quantification.

\begin{tabular}{|c|c|c|c|}
\hline & \multicolumn{2}{|c|}{ Analyte concentration $(\mathrm{ng} / \mathrm{mL})$} & \multirow{2}{*}{$\begin{array}{c}0.990 \\
\text { Signal/noise ratio }\end{array}$} \\
\hline & Conc. (ng/mL) & $\%$ nominal & \\
\hline & 0.989 & 99.945 & 44.500 \\
\hline & 1.407 & 142.094 & 36.000 \\
\hline & 0.958 & 96.802 & 46.100 \\
\hline & 1.167 & 117.863 & 31.700 \\
\hline & 1.175 & 118.723 & 41.500 \\
\hline & 1.241 & 125.400 & 48.800 \\
\hline $\mathrm{N}$ & 6 & 6 & 6 \\
\hline Mean & 1.156 & 116.804 & 41.433 \\
\hline $\mathrm{SD}( \pm)$ & 0.166 & & \\
\hline \multirow[t]{6}{*}{$\mathrm{CV}(\%)$} & 14.339 & & \\
\hline & \multicolumn{2}{|c|}{ Acceptance criteria } & \\
\hline & \multirow{4}{*}{\multicolumn{2}{|c|}{$\begin{array}{c}4 \text { out of } 6 \text { LLQC must be } 100 \pm 20 \% \text { nominal value. } \\
\text { Mean } \% \text { nominal } 100 \pm 20 \% \\
\text { CV }(\%) \leq 20 \% \\
\text { Signal/noise ratio } \geq 5\end{array}$}} & \\
\hline & & & \\
\hline & & & \\
\hline & & & \\
\hline
\end{tabular}

TABLE 2: Evaluation of intraday precision and accuracy for bisoprolol spiked quality control samples.

\begin{tabular}{|c|c|c|c|c|c|c|}
\hline \multicolumn{3}{|c|}{$\mathrm{C}_{\mathrm{th}}=3 \mathrm{ng} / \mathrm{mL}$} & \multicolumn{2}{|c|}{$\mathrm{C}_{\mathrm{th}}=25 \mathrm{ng} / \mathrm{mL}$} & \multicolumn{2}{|c|}{$\mathrm{C}_{\mathrm{th}}=75 \mathrm{ng} / \mathrm{mL}$} \\
\hline & $\mathrm{C}_{\exp }(\mathrm{ng} / \mathrm{mL})$ & $\%$ nominal & $\mathrm{C}_{\exp }(\mathrm{ng} / \mathrm{mL})$ & $\%$ nominal & $\mathrm{C}_{\exp }(\mathrm{ng} / \mathrm{mL})$ & $\%$ nominal \\
\hline (1) & 2.912 & 98.391 & 22.524 & 91.263 & 69.203 & 93.468 \\
\hline (2) & 3.003 & 101.439 & 24.862 & 100.737 & 68.525 & 92.552 \\
\hline (3) & 3.262 & 110.192 & 23.762 & 96.281 & 66.781 & 90.196 \\
\hline (4) & 2.829 & 95.568 & 25.189 & 102.062 & 76.691 & 103.580 \\
\hline (5) & 3.018 & 101.960 & 21.739 & 88.085 & 65.844 & 88.931 \\
\hline (6) & 2.854 & 96.431 & 21.371 & 86.593 & 74.009 & 99.958 \\
\hline Mean & 2.980 & 100.664 & 23.241 & 94.170 & 70.176 & 94.781 \\
\hline SD & 0.158 & & 1.610 & & 4.268 & \\
\hline $\mathrm{CV} \%$ & 5.296 & & 6.927 & & 6.082 & \\
\hline
\end{tabular}

$67 \%$ Total QCs must be $100 \pm 15 \%$ nominal values

$50 \%$ QCs per level must be $100 \pm 15 \%$ nominal values

Mean $\%$ nominal $100 \pm 15 \%$

$\mathrm{CV}(\%) \leq 15 \%$

$\mathrm{C}_{\mathrm{th}}=$ theoretical concentration. $\mathrm{C}_{\mathrm{exp}}=$ experimental concentration. $\mathrm{SD}=$ standard deviation. $\mathrm{CV} \%=$ coefficient of variation

six aliquots for each quality control sample concentration, prepared and analysed in six different days. The results are presented in Table 3.

Intra-and interday precision of analysis was $<8 \%$ and accuracy range was from $94.170 \%$ to $102.540 \%$.

The values for the investigated parameters proved to be lower than the one reported by Oniscu et al. [6], employing a HPLC method with fluorescence detection. Also, Liu et al. [7] reported an accuracy ranged from $89.4 \%-113 \%$, employing a precipitation with acetonitrile procedure for plasma sample preparations.

3.2.4. Recovery. Recovery of Bisoprolol was evaluated by comparing analyte response of six extracted samples of low, medium, and high quality control samples to those of six appropriately diluted standard solutions. Mean recovery values for Bisoprolol are 76.529, 78.479, and 79.863\% at low, medium and high quality control levels, respectively.

For internal standard, mean internal standard response of eighteen extracted samples was compared to the mean internal standard responses of eighteen appropriately diluted internal standard solutions. Mean recovery value for the internal standard is $90.568 \%$.

3.2.5. Stability Tests. To test stability, a series of standards samples was prepared from freshly made stock solutions in the same solvent used for the assay. The lowest and highest concentration of the quality control $(3 \mathrm{ng} / \mathrm{mL}$ and 
TABLE 3: Evaluation of interday precision and accuracy for bisoprolol spiked quality control samples.

\begin{tabular}{|c|c|c|c|c|c|c|}
\hline \multicolumn{3}{|c|}{$\mathrm{C}_{\mathrm{th}}=3 \mathrm{ng} / \mathrm{mL}$} & \multicolumn{2}{|c|}{$\mathrm{C}_{\mathrm{th}}=25 \mathrm{ng} / \mathrm{mL}$} & \multicolumn{2}{|c|}{$\mathrm{C}_{\mathrm{th}}=75 \mathrm{ng} / \mathrm{mL}$} \\
\hline & $\mathrm{C}_{\exp }(\mathrm{ng} / \mathrm{mL})$ & Accuracy $(\%)$ & $\mathrm{C}_{\exp }(\mathrm{ng} / \mathrm{mL})$ & Accuracy $(\%)$ & $\mathrm{C}_{\exp }(\mathrm{ng} / \mathrm{mL})$ & Accuracy (\%) \\
\hline (1) & 3.015 & 101.860 & 24.331 & 98.586 & 70.921 & 95.788 \\
\hline (2) & 2.879 & 97.276 & 23.332 & 94.539 & 77.073 & 104.097 \\
\hline (3) & 3.257 & 110.048 & 23.109 & 93.636 & 77.932 & 105.256 \\
\hline (4) & 2.964 & 100.136 & 24.013 & 97.297 & 70.590 & 95.340 \\
\hline (5) & 2.943 & 99.439 & 28.411 & 115.117 & 75.582 & 102.083 \\
\hline (6) & 3.152 & 106.480 & 24.910 & 100.933 & 74.865 & 101.115 \\
\hline Mean & 3.035 & 102.540 & 24.684 & 100.018 & 74.494 & 100.613 \\
\hline SD & 0.142 & & 1.940 & & 3.092 & \\
\hline $\mathrm{CV} \%$ & 4.686 & & 7.860 & & 4.151 & \\
\hline \multicolumn{7}{|c|}{ Acceptance criteria } \\
\hline \multicolumn{7}{|c|}{$67 \%$ Total QCs must be $100 \pm 15 \%$ nominal values } \\
\hline \multicolumn{7}{|c|}{$50 \%$ QCs per level must be $100 \pm 15 \%$ nominal values } \\
\hline \multicolumn{7}{|c|}{ Mean $\%$ nominal $100 \pm 15 \%$} \\
\hline & & & $\mathrm{CV}(\%) \leq$ & & & \\
\hline
\end{tabular}

TABLE 4: Stability of analyte following sample processing at room temperature.

\begin{tabular}{|c|c|c|c|c|c|c|}
\hline & \multicolumn{2}{|c|}{ Analyte: } & Bisoprolol & & & \\
\hline & \multicolumn{2}{|c|}{ Biological matrix: } & Human Plasma & & & \\
\hline & \multicolumn{2}{|c|}{ Storage condition: } & \multicolumn{2}{|c|}{31 Hours at Room Temperature } & & \\
\hline & \multicolumn{3}{|c|}{$\mathrm{QC1}(3 \mathrm{ng} / \mathrm{mL})$} & \multicolumn{3}{|c|}{ QC3 (75 ng/mL) } \\
\hline & \multicolumn{2}{|c|}{ Comparison Samples } & Stability Samples & \multicolumn{2}{|c|}{ Comparison Samples } & \multirow{2}{*}{$\begin{array}{c}\text { Stability Samples } \\
\text { Measured }\end{array}$} \\
\hline & Measured & $\%$ nominal & Measured & Measured & $\%$ nominal & \\
\hline & Conc. & & Conc. & Conc. & & Conc. \\
\hline & 2.682 & 90.611 & 2.838 & 80.224 & 108.352 & 82.798 \\
\hline & 2.330 & 78.719 & 2.639 & 82.755 & 111.771 & 63.262 \\
\hline & 3.082 & 104.134 & 2.434 & 78.821 & 106.457 & 75.379 \\
\hline & 2.380 & 80.392 & 2.079 & 79.826 & 107.815 & 80.616 \\
\hline & 2.117 & 71.504 & 2.047 & 91.323 & 123.343 & 58.511 \\
\hline & 2.619 & 88.475 & 2.745 & 84.105 & 113.595 & 79.410 \\
\hline $\mathrm{N}$ & 6 & 6 & 6 & 6 & 6 & 6 \\
\hline Mean & 2.535 & 85.639 & 2.464 & 82.842 & 111.889 & 73.329 \\
\hline $\mathrm{SD}( \pm)$ & 0.338 & & 0.338 & 4.597 & & 10.049 \\
\hline $\mathrm{CV}(\%)$ & 13.314 & & 13.734 & 5.549 & & 13.704 \\
\hline \multirow[t]{6}{*}{$\%$ Change } & & -2.808 & & & -11.483 & \\
\hline & \multicolumn{5}{|c|}{ Acceptance criteria } & \\
\hline & \multicolumn{5}{|c|}{$67 \%$ comparison samples must be $100 \pm 15 \%$ nominal values } & \\
\hline & \multicolumn{5}{|c|}{ Mean $\%$ nominal of comparison samples $100 \pm 15 \%$} & \\
\hline & \multicolumn{5}{|c|}{$\mathrm{CV}(\%) \leq 15 \%$} & \\
\hline & \multicolumn{5}{|c|}{$\%$ Change $\pm 15 \%$} & \\
\hline
\end{tabular}

$75 \mathrm{ng} / \mathrm{mL}$ ), including the analyte and internal standard (when appropiate) were used. Human plasma samples of each concentration were prepared in enough volume to have multiple aliquots. The aliquots of each concentration were processed and quantified immediately in order to provide the reference (fresh) values and other six aliquots of each concentration were processed for the desired tests.

The following subsections present the procedure carried out and the corresponding results. (a) Stability of the Analyte after Sample Processing at Room Temperature. Samples prepared at low (QC1) and high (QC3) quality control levels were submitted to the extraction procedure and kept at room temperature under ambient laboratory conditions (stability samples). A calibration curve and 6 replicates of low and high quality control samples (comparison samples) were freshly processed and analyzed with 6 replicates of stability samples in a single run. Concentrations were calculated to determine $\%$ change over time. 
TABLE 5: Stability of analyte in biological matrix at room temperature.

\begin{tabular}{|c|c|c|c|c|c|c|}
\hline & \multicolumn{2}{|c|}{ Analyte: } & Bisoprolol & & & \\
\hline & \multicolumn{2}{|c|}{ Biological matrix: } & Human plasma & & & \\
\hline & \multicolumn{2}{|c|}{ Storage condition: } & & \multicolumn{3}{|c|}{4 Hours at Room Temperature } \\
\hline & \multicolumn{2}{|c|}{$\mathrm{QC1}(3 \mathrm{ng} / \mathrm{mL})$} & & \multicolumn{3}{|c|}{ QC3 (75 ng/mL) } \\
\hline & \multicolumn{2}{|c|}{ Comparison Samples } & Stability Samples & \multicolumn{2}{|c|}{ Comparison Samples } & \multirow{2}{*}{$\begin{array}{c}\text { Stability Samples } \\
\text { Measured }\end{array}$} \\
\hline & Measured & $\%$ nominal & Measured & Measured & $\%$ nominal & \\
\hline & Conc. & & Conc. & Conc. & & Conc. \\
\hline & 3.509 & 118.561 & 3.540 & 61.764 & 83.419 & 72.020 \\
\hline & 2.839 & 95.898 & 3.502 & 74.312 & 100.368 & 67.462 \\
\hline & 3.453 & 116.639 & 3.281 & 73.697 & 99.537 & 90.117 \\
\hline & 3.187 & 107.684 & 3.514 & 72.186 & 97.495 & 73.715 \\
\hline & 4.310 & 145.604 & 3.616 & 68.557 & 92.595 & 69.225 \\
\hline & 3.123 & 105.510 & 3.688 & 75.832 & 102.421 & 69.012 \\
\hline $\mathrm{N}$ & 6 & 6 & 6 & 6 & 6 & 6 \\
\hline Mean & 3.403 & 114.983 & 3.523 & 71.058 & 95.973 & 73.592 \\
\hline $\mathrm{SD}( \pm)$ & 0.506 & & 0.138 & 5.182 & & 8.405 \\
\hline $\mathrm{CV}(\%)$ & 14.864 & & 3.925 & 7.292 & & 11.421 \\
\hline \multirow[t]{6}{*}{$\%$ Change } & & 3.522 & & & 3.566 & \\
\hline & \multicolumn{5}{|c|}{ Acceptance criteria: } & \\
\hline & \multicolumn{5}{|c|}{$67 \%$ comparison samples must be $100 \pm 15 \%$ nominal values } & \\
\hline & \multicolumn{5}{|c|}{ Mean $\%$ nominal of comparison samples $100 \pm 15 \%$} & \\
\hline & \multicolumn{5}{|c|}{$\mathrm{CV}(\%) \leq 15 \%$} & \\
\hline & \multicolumn{5}{|c|}{$\%$ Change $\pm 15 \%$} & \\
\hline
\end{tabular}

TABLE 6: Stability of analyte in biological matrix after 3 freeze-thaw cycles at $-25 \pm 10^{\circ} \mathrm{C}$.

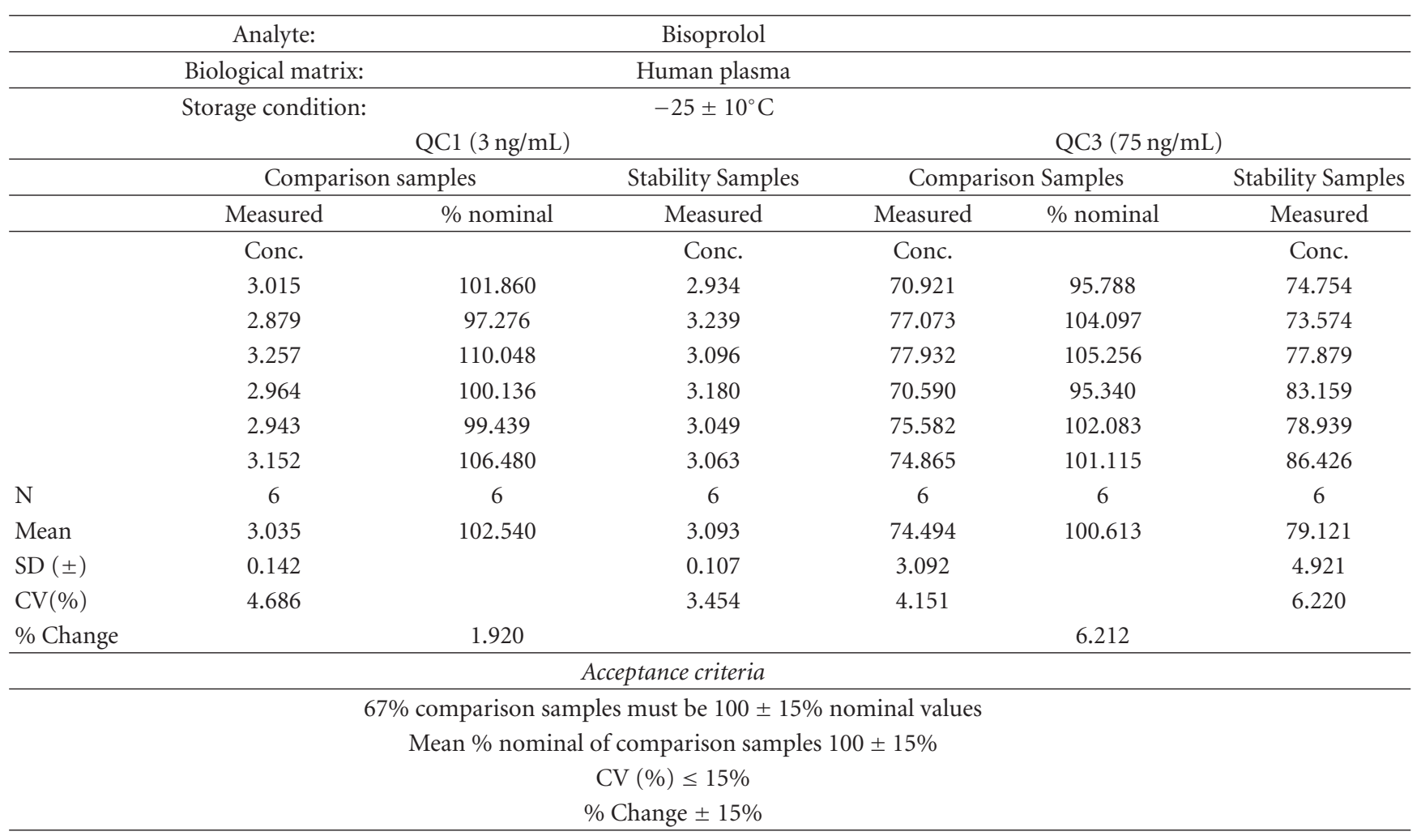




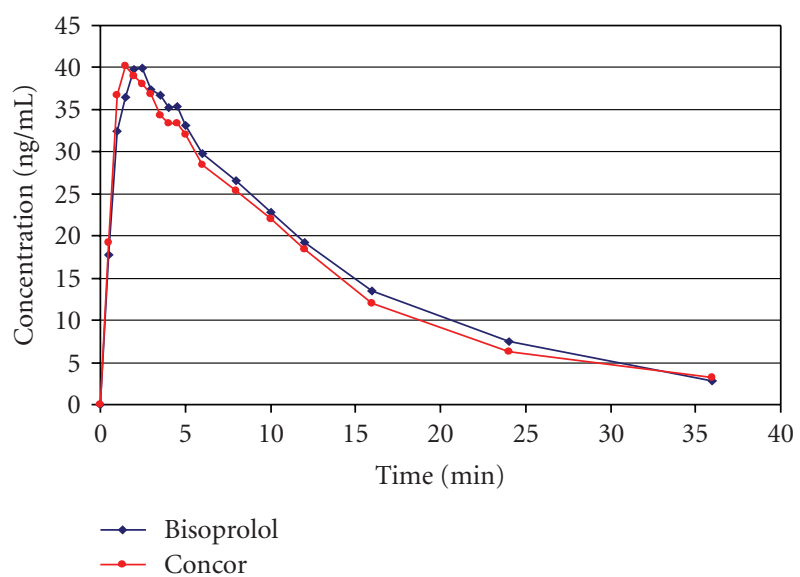

FIgURe 4: Average bisoprolol concentrations recorded for the test and reference drugs in the bioequivalence study performed on 22 healthy volunteers.

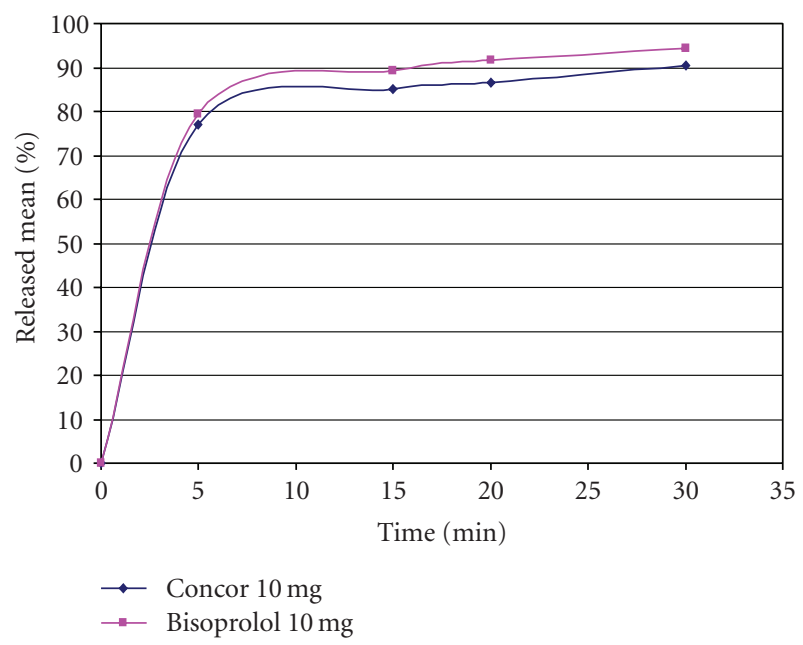

Figure 5: Average dissolved bisoprolol recorded for test and reference drugs recorded for the in vitro dissolution test.

Bisoprolol is found to be stable for 31 hours at room temperature under ambient laboratory conditions after sample processing with \% changes (ratio between mean concentration of stability samples and mean concentration of comparison samples) of -11.483 and $-2.808 \%$. Results are presented in Table 4.

(b) Stability of Analyte in Biological Matrix at Room Temperature. Samples were prepared at low (QC1) and high (QC3) quality control levels. Six replicates of low and high quality control samples were left at room temperature for approximately 4 hours (stability samples). A calibration curve and 6 replicates of low and high quality control samples (comparison samples) were freshly processed with 6 replicates of stability samples and analyzed in a single run. Concentrations were calculated to determine $\%$ change over time.
Bisoprolol is found to be stable in human plasma for 4 hours at room temperature with \% changes of 3.522 and $3.566 \%$. Results are presented in Table 5.

(c) Stability of Analyte in Biological Matrix after 3 FreezeThaw Cycles. Samples were prepared at low (QC1) and high (QC3) quality control levels, aliquoted and frozen at $-25 \pm$ $10^{\circ} \mathrm{C}$. Some of the aliquots of quality control samples were subjected to three freeze-thaw cycles (stability samples). The remaining aliquots were not thawed (comparison samples). A calibration curve and 6 replicates of low and high quality control samples (comparison samples) were freshly processed with 6 replicates of stability samples and analyzed in a single run. Concentrations were calculated to determine $\%$ change over freeze-thaw cycles. Bisoprolol is found to be stable in human plasma after three freeze-thaw cycles with $\%$ changes of 1.920 and $6.212 \%$. Results are presented in Table 6.

3.3. The Applications of LC-Tandem Mass Spectrometry Method. The assay has proven to be suitable to determine the bisoprolol concentration in the bioequivalence study of Bisoprolol $10 \mathrm{mg}$ coated tablets produced by Antibiotice S.A. (referred to as test drug) versus Concor ${ }^{\circledR} 10 \mathrm{mg}$ coated tablets produced by Merck (referred to as reference drug). In Figure 4, average bisoprolol concentrations recorded for 22 volunteers are plotted against time for both test and reference drugs.

The concentration profiles are similarly, fitting the results obtained for the in vitro dissolution test (see Figure 5).

Based on the determined bisoprolol concentrations, the calculated pharmacokinetic parameters demonstrated that the drug produced by Antibiotice S.A. is bioequivalent with the one produced by Merck.

\section{Conclusions}

LC-tandem mass spectrometry method described and validated above is sensitive, accurate, precise, rapid, and efficient. The developed method can be applied for the determination of bisoprolol from human plasma samples (e.g., for pharmacokinetic parameters).

\section{References}

[1] "Bisoprolol," in Clarkes's Analysis of Drugs and Poisons, vol. 1, Pharmaceutical Press, London, UK, 2005.

[2] M. D. Hernando, M. Petrovic, A. R. Fernández-Alba, and D. Barceló, "Analysis by liquid chromatography-electrospray ionization tandem mass spectrometry and acute toxicity evaluation for $\beta$-blockers and lipid-regulating agents in wastewater samples," Journal of Chromatography A, vol. 1046, no. 1-2, pp. 133-140, 2004.

[3] S. Li, G. Liu, J. Jia, et al., "Simultaneous determination of ten antiarrhythmics drugs and a metabolite in human plasma by liquid chromatography-tandem mass spectrometry," Journal of Chromatography B, vol. 847, no. 2, pp. 174-181, 2007.

[4] J. Bhatt, G. Subbaiah, S. Kambli, et al., "A high throughput and sensitive liquid chromatography-tandem mass spectrometry 
(LC-MS/MS) method for the estimation of bisoprolol in human plasma using multiplexing technique," Journal of Chromatography B, vol. 852, no. 1-2, pp. 374-381, 2007.

[5] F.D.A., Center for Drug Evaluation and Research (CDER), "Guidance for Industry: Bioanalytical Method Validation," May 2001.

[6] C. Oniscu, C. V. Vlase, and G. Peste, "A new high performance liquid chromatographic method for determination of bisoprolol in plasma samples," Roumanian Biotechnological Letters, vol. 12, no. 1, pp. 3079-3084, 2007.

[7] M. Liu, D. Zhang, Y. Sun, Y. Wang, Z. Liu, and J. Gu, "Liquid chromatographic-electrospray tandem mass spectrometric determination of bisoprolol in human plasma," Biomedical Chromatography, vol. 21, no. 5, pp. 508-513, 2007. 

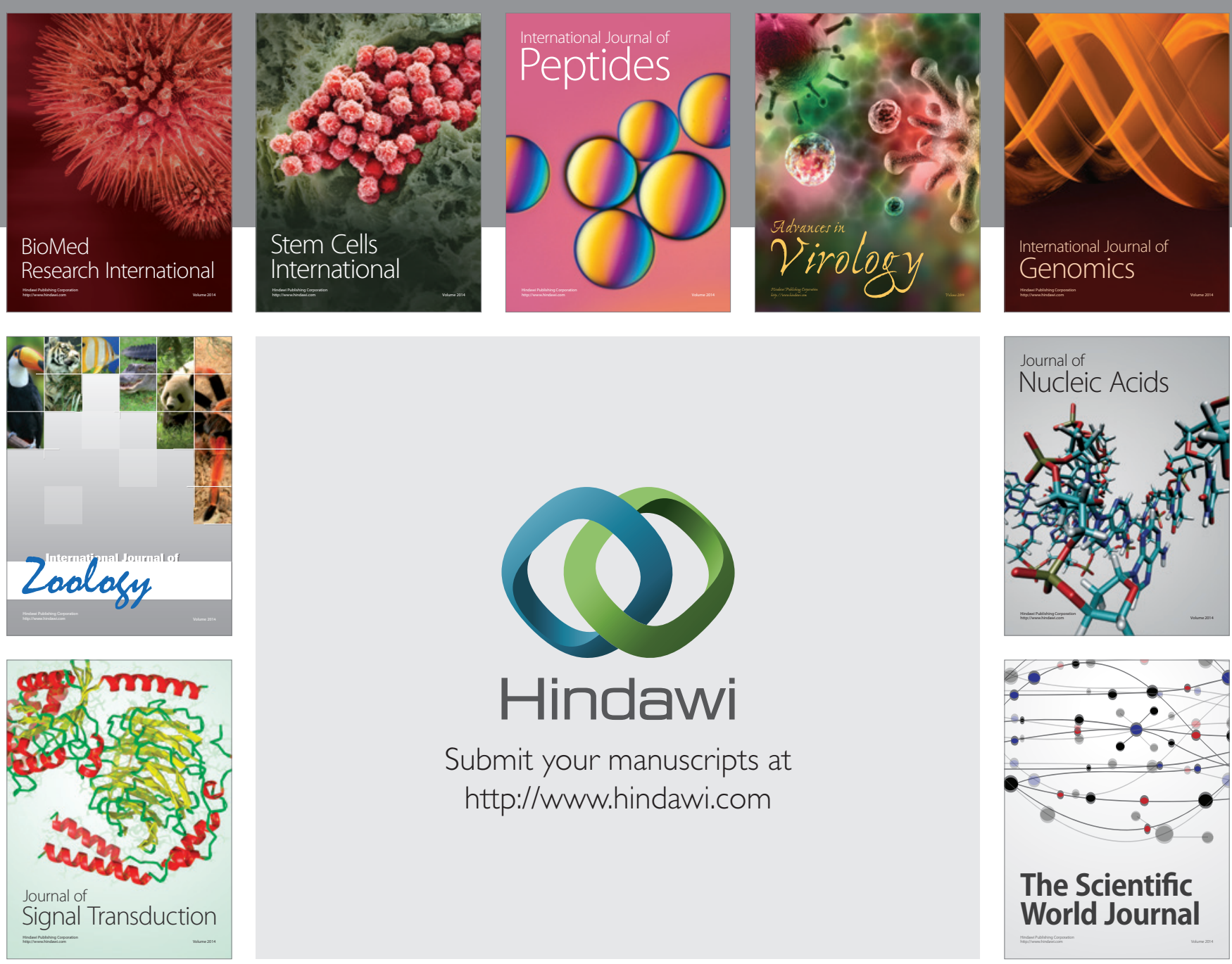

Submit your manuscripts at

http://www.hindawi.com
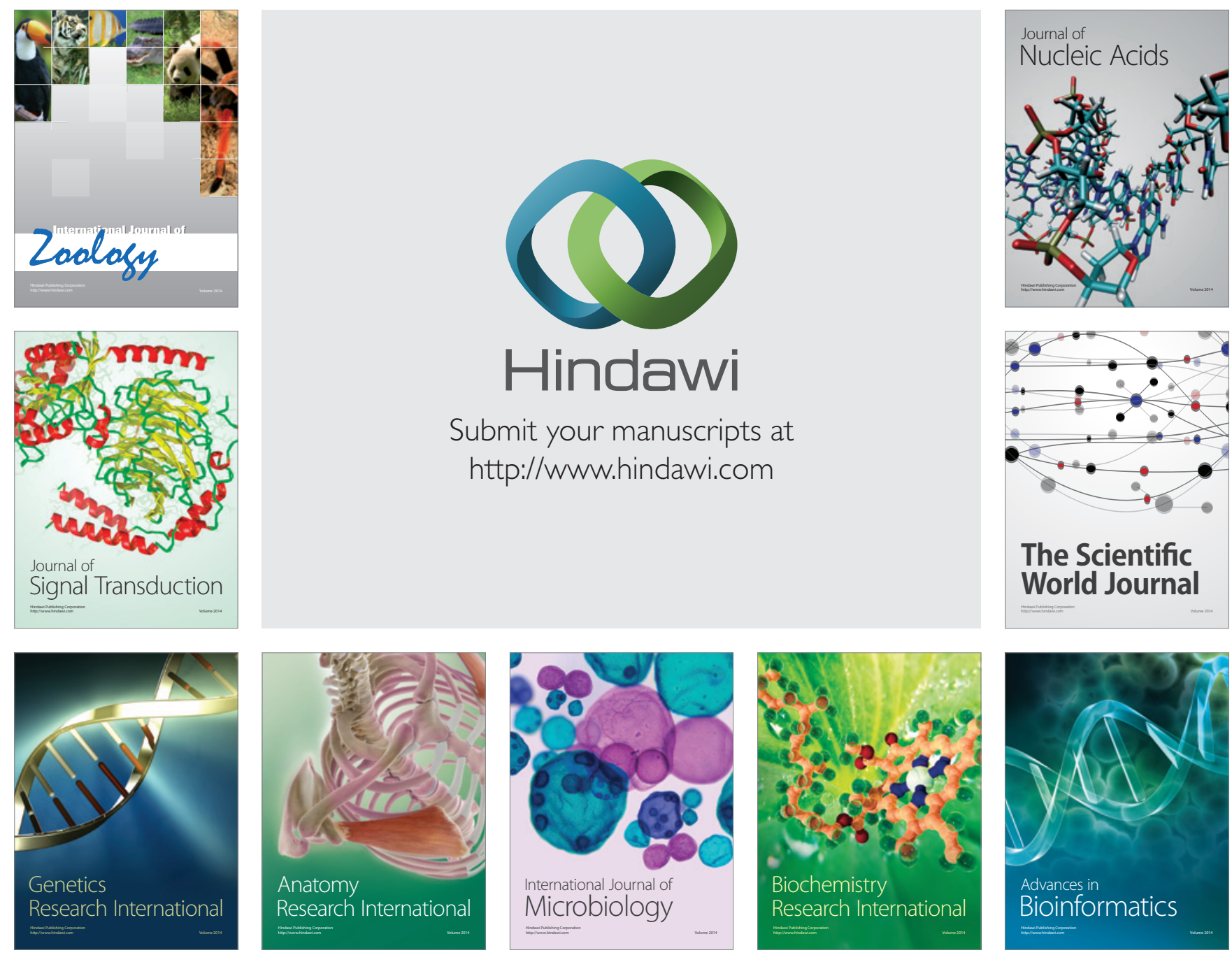

The Scientific World Journal
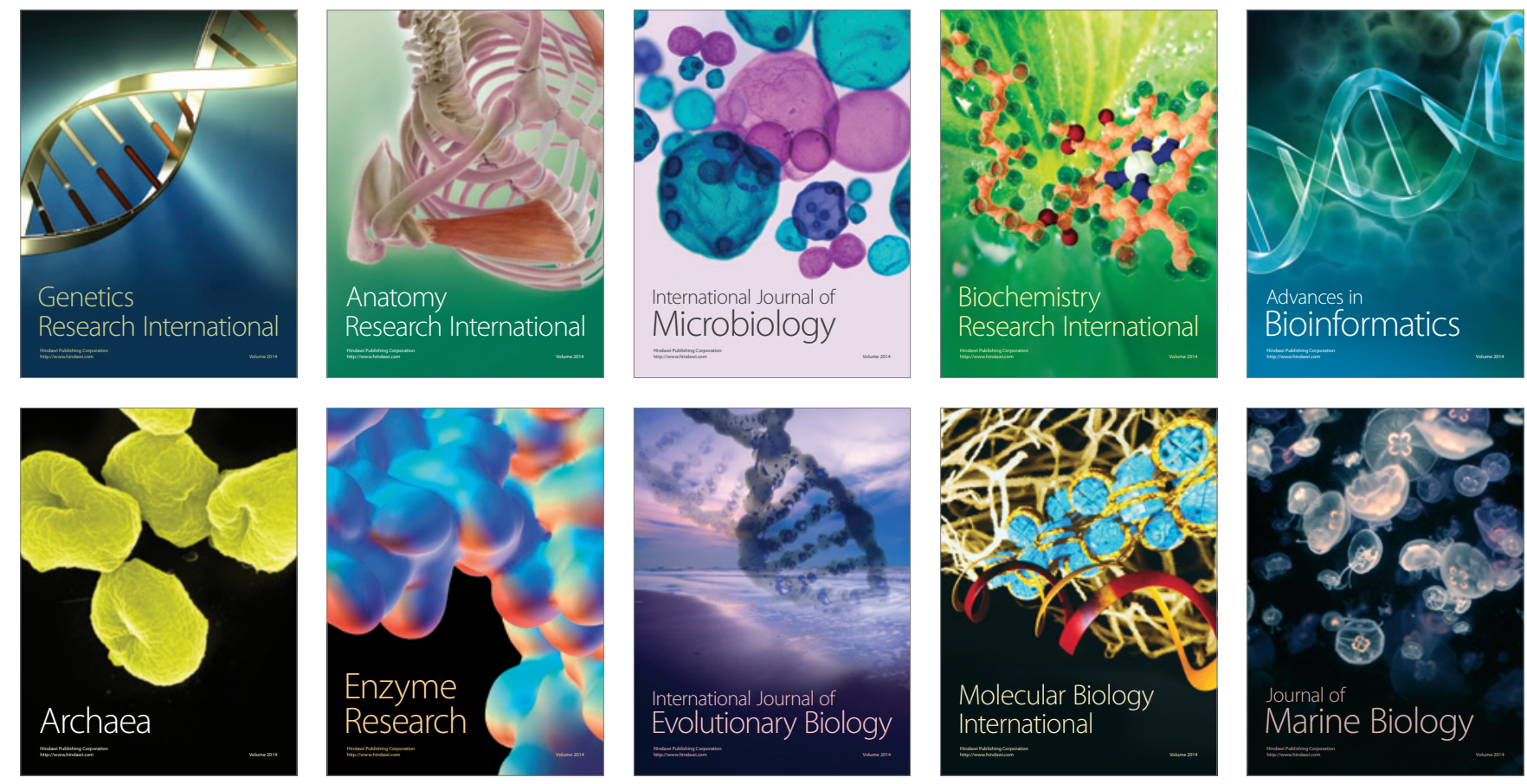